\title{
TWO, FIVE, SIX, EIGHT (THOUSAND): TIME TO END THE DIMENSION REDUCTION DEBATE!
}

\author{
BRENTON M. WIERNIK ${ }^{1}{ }^{D}$, TAL YARKONI $^{2}$, CASEY A. GIORDANO ${ }^{\circledR}$, and MUKHUNTH \\ RAGHAVAN $^{1}$ \\ ${ }^{1}$ University of South Florida \\ 2 University of Texas at Austin \\ 3 University of Minnesota \\ brenton@wiernik.org
}

A commentary to appear with:

Ashton, M. C., \& Lee, K. (2020). Objections to the HEXACO model of personality structure-and why those objections fail. European Journal of Personality. https://doi.org/10.1002/per.2242

Abstract: In the latest salvo in the century-long lexical-dimensionality-reduction debate (Galton, 1884), Ashton and Lee (2020) argue their HEXACO model is superior to Big Five models. We argue that debates comparing alternative low-dimensional personality structures no longer advance personality science or practice. Instead, researchers should embrace the inherent complexity and high dimensionality of human individual differences. If a low-dimensional model is used, investigators should choose a model based on its coherent representation of traits they deem meaningful for the research domain, rather than its alignment with a specific factor analysis solution.

Keywords: personality, dimension reduction, philosophy of science, realism

Ashton and Lee (2020) argue their six-dimensional "HEXACO" framework is a more accurate and useful description of the personality space than existing five-dimensional models. This argument rests on strong modeling assumptions and preferences that Ashton and Lee do not clearly articulate or justify, and with which many researchers can reasonably disagree. We argue that any attempt to carve personality space into a low-dimensional (e.g., five- or sixfactor) solution necessarily discards important information and likely cannot uncover the true data-generating mechanism. Accordingly, we call for a moratorium on attempts to identify a universally optimal low-dimensional personality structure. Instead, we argue that personality model selection should be based on the specific application at hand and can reasonably be informed by a wide array of concerns.

\section{THE STRUCTURE OF PERSONALITY}

Personality traits can be meaningfully described at multiple levels of complexity (Ones et al., 2016).
At the highly-abstract end, broad patterns of trait covariation might be described in terms of two, three, four, or five dimensions (Markon, 2009). A less abstract, but still comparatively low-dimensional, solution might describe personality in terms of 15 , 27, or 36 narrower traits (Condon, 2018; Soto \& John, 2017; Stanek \& Ones, 2018). But none of these should be mistaken for the true data-generating process that produces scale responses. A complete personality phenotype would minimally involve hundreds of specific characteristics (McAdams, 1994). Biologically, human thought, affect, and behavior is driven by thousands of genes and complex interactions among hundreds of neural structures, neurotransmitters, hormones, and other factors (Yarkoni, 2015). Any low-dimensional solution must therefore be deficient and understood merely as a potentially useful oversimplification.

Ashton and Lee's argument for the HEXACO model relies on strong assumptions - e.g., (1) the lexicon is a representative basis for personality 
description; (2) exploratory factor analysis (EFA) ${ }^{1}$ should be preferred over other dimension-reduction techniques; (3) nature has a predilection for "simple structure" and relatively orthogonal dimensions; and (4) cross-cultural replicability should be a primary concern. These are strong assumptions that some researchers (like Ashton and Lee) may subscribe to, but that many other researchers are unlikely to share. Lexical analyses and dimensionality-reduction methods are tools to explore rough contours of the personality space. We should not, however, delude ourselves into thinking that we are slicing nature at its joints to discover a "true" structure of personality.

\section{CHOOSING A PERSONALITY MODEL}

Considering that all low-dimensional representations of personality are necessarily wrong, model choice should be guided by the assessment purpose. If one's goal is maximizing predictive validity, itemlevel composites empirically-keyed for specific outcomes using large samples will almost invariably outperform any limited set of broad factors (Mõttus et al., 2017; Revelle et al., 2020; Saucier et al., 2020). When predicting multiple criteria, Pareto-optimality approaches build models that balance the prediction across criteria. When large-scale item-level modeling is infeasible, predictive models built on narrow "facet-level" scales will certainly outperform five- or six-dimensional models. Another option when largescale modeling is infeasible is to rationally prescreen a set of traits for strong a priori relevance for the outcome content (e.g., together, measures of integrity, ambition, and Openness would reasonably and efficiently predict most job performance dimensions; Connelly et al., 2018).

By contrast, if the assessment purpose is to explore personality development in response to situations and experiences, investigators should focus on coherent measurement of personality constructs they deem important to the research domain. Personality constructs are folk concepts_-pragmatic fictions, descriptions of meaningful clusters of related

\footnotetext{
${ }^{1}$ Or principal components analysis.

${ }^{2}$ Negative Urgency, Premeditation, Perseverance, Sensation Seeking, Positive Urgency (Cyders et al., 2007).

${ }^{3}$ Notably, mechanical composites are rarely used in decisionmaking practice, so multiple-regression-based validity only
}

personal tendencies (Tellegen, 1993). What constitutes a "meaningful" cluster will, naturally, depend on an investigator's goals, and to some degree, on aesthetic preferences. For example, if a researcher studying impulsive behavior finds the UPPS-P model $^{2}$ to be an intuitive, parsimonious way to carve up that space, they should not be bothered that these dimensions don't fit neatly into either the Big Five or HEXACO spaces. Similarly, if a neurobiologist finds it useful to identify biological mechanisms associated with "non-traditional" psychometric dimensions (e.g., agentic and affiliative systems rather than their more "standard" Extraversion-Agreeableness rotation; Depue \& Collins, 1999), we would consider efforts to "correct" them based on large-scale lexical EFAs peculiar or obnoxious.

A third common desideratum is interpretabilityi.e., intuitiveness and accessibility of personality information when humans must judge the results (e.g., counseling). Users must readily understand the meaning of scale scores and their implications, even with some loss regression-based predictive accuracy. ${ }^{3}$ For example, a hiring manager might find a model grouping all traits related to "helpfulness" under one dimension (e.g., Big Five models) more intuitive than a model splitting these tendencies across multiple dimensions (e.g., the HEXACO model). Memorability and flair are also critical considerations for applied assessment-we should not discount the value of "The OCEAN of personality" (Openness, Conscientiousness, Extraversion, Agreeableness, Negative Emotionality) as an evocative and appealing mnemonic device ${ }^{4}$. Applied personality models must guide practitioners toward better decisions, not slavishly reflect results of a particular dimensionality-reduction procedure.

These considerations are by no means exhaustive; many other model prioritization criteria are possible. We are not suggesting it is wrong to prioritize a solution that, say, maximizes cross-country replicability of oblimin-rotated factor solutions of lexical

approximates the practical utility of a set of personality scales (Kuncel et al., 2013).

${ }^{4}$ Such appeal is especially important to attract test-users over type-based models like the Myers-Briggs Type Indicator. 
descriptors $^{5}$. We simply observe that it reflects just one narrow set of assumptions, and researchers who don't share Ashton and Lee's specific priorities shouldn't feel pressure to use HEXACO (or, for that matter, the Big Five). We should be leery of arguments that privilege specific priorities, particularly when arguments for the superiority of HEXACO come from "the same people who identified the HEXACO model and constructed the HEXACO inventory" and "receive royalty payments for non-academic use of that inventory" (Ashton \& Lee, 2020, p. 5).

\section{CONCLUSION}

Low-dimensional personality models have historically been useful for describing the broad contours of personality variation and providing a lexicon for organizing personality research (John et al., 2008). But debates comparing alternative low-dimensional solutions now generate far more heat than light. It's time for personality research to embrace the natural complexity of human individual differences.

\section{REFERENCES}

Ashton, M. C., \& Lee, K. (2020). Objections to the HEXACO model of personality structure-And why those objections fail. European Journal of Personality. Advance online publication. https://doi.org/10.1002/per.2242

Condon, D. M. (2018). The SAPA Personality Inventory: An empirically-derived, hierarchically-organized self-report personality assessment model. PsyArXiv. https://doi.org/10.31234/osf.io/sc4p9

Connelly, B. S., Ones, D. S., \& Hülsheger, U. R. (2018). Personality in industrial, work and organizational psychology: Theory, measurement and application. In D. S. Ones, N. Anderson, C. Viswesvaran, \& H. K. Sinangil (Eds.), The SAGE handbook of industrial, work and organizational psychology (2nd ed., Vol. 1, pp. 320-365). Sage. https://doi.org/10.4135/9781473914940.n13

Cyders, M. A., Smith, G. T., Spillane, N. S., Fischer, S., Annus, A. M., \& Peterson, C. (2007). Integration of impulsivity and positive mood to predict risky behavior: Development and validation of a measure of positive urgency. Psychological Assessment, 19(1), 107-118. https://doi.org/10.1037/1040-3590.19.1.107

\footnotetext{
${ }^{5}$ If cross-cultural lexical factor replicability is prioritized, then two dimensions should probably be preferred (Saucier et al., 2014), as no more than 2-3 dimensions consistently emerge
}

De Raad, B., Barelds, D. P. H., Levert, E., Ostendorf, F., Mlačić, B., Blas, L. D., Hřebíčková, M., Szirmák, Z., Szarota, P., Perugini, M., Church, A. T., \& Katigbak, M. S. (2010). Only three factors of personality description are fully replicable across languages: A comparison of 14 trait taxonomies. Journal of Personality and Social Psychology, 98(1), 160-173. https://doi.org/10.1037/a0017184

Depue, R. A., \& Collins, P. F. (1999). Neurobiology of the structure of personality: Dopamine, facilitation of incentive motivation, and extraversion. Behavioral and Brain Sciences, 22(3), 491-517. https://doi.org/10.1017/s0140525x99002046

Galton, F. (1884). Measurement of character. Fortnightly Review, 36, 179-185. http://galton.org/bib/JournalItem.aspx action $=$ view id $=133$

John, O. P., Naumann, L. P., \& Soto, C. J. (2008). Paradigm shift to the integrative Big Five trait taxonomy: History, measurement, and conceptual issues. In O. P. John, R. W. Robins, \& L. A. Pervin (Eds.), Handbook of personality: Theory and research (3rd ed., pp. 114-158). Guilford Press. Kuncel, N. R., Klieger, D. M., Connelly, B. S., \& Ones, D. S. (2013). Mechanical versus clinical data combination in selection and admissions decisions: A meta-analysis. Journal of Applied Psychology, 98(6), 1060-1072. https://doi.org/10.1037/a0034156

Markon, K. E. (2009). Hierarchies in the structure of personality traits. Social and Personality Psychology Compass, 3(5), 812-826. https://doi.org/10.1111/j.1751-9004.2009.00213.x

McAdams, D. P. (1994). A psychology of the stranger. Psychological Inquiry, 5(2), 145-148. https://doi.org/10.1207/s15327965pli0502_12

Mõttus, R., Bates, T. C., Condon, D. C., Mroczek, D. K., \& Revelle, W. R. (2017). Leveraging a more nuanced view of personality: Narrow characteristics predict and explain variance in life outcomes. PsyArXiv. https://doi.org/10.31234/osf.io/4q9gv

Ones, D. S., Wiernik, B. M., Wilmot, M. P., \& Kostal, J. W. (2016). Conceptual and methodological complexity of narrow trait measures in personality-outcome research: Better knowledge by partitioning variance from multiple latent traits and measurement artifacts. European Journal of Personality, 30(4), 319-321. https://doi.org/10.1002/per.2060

Revelle, W., Dworak, E. M., \& Condon, D. M. (2020). Exploring the persome: The power of the item in understanding personality structure. Personality and Individual Differences, 109905. https://doi.org/10.1016/j.paid.2020.109905

Saucier, G., Iurino, K., \& Thalmayer, A. G. (2020). Comparing predictive validity in a community sample: High-dimensionality and traditional domain-and-facet structures of personality variation. European Journal of Personality. https://doi.org/10.1002/per.2235

cross-culturally (De Raad et al., 2010). Indicator cross-loading patterns are even less consistent across cultures. 
Saucier, G., Thalmayer, A. G., Payne, D. L., Carlson, R., Sanogo, L., Ole-Kotikash, L., Church, A. T., Katigbak, M. S., Somer, O., Szarota, P., Szirmák, Z., \& Zhou, X. (2014). A basic bivariate structure of personality attributes evident across nine languages. Journal of Personality, 82(1), 1-14. https://doi.org/10.1111/jopy.12028

Soto, C. J., \& John, O. P. (2017). The next Big Five Inventory (BFI-2): Developing and assessing a hierarchical model with 15 facets to enhance bandwidth, fidelity, and predictive power. Journal of Personality and Social Psychology, 113(1), 117-143. https://doi.org/10.1037/pspp0000096

Stanek, K. C., \& Ones, D. S. (2018). Taxonomies and compendia of cognitive ability and personality measures relevant to industrial, work, and organizational psychology. In D. S. Ones, N. Anderson, C. Viswesvaran, \& H. K. Sinangil (Eds.), The SAGE handbook of industrial, work and organizational psychology: Vol. 1: Personnel psychology and employee performance (2nd ed., pp. 366-407). Sage. https://doi.org/10.4135/9781473914940.n14

Tellegen, A. (1993). Folk concepts and psychological concepts of personality and personality disorder. Psychological Inquiry, 4(2), 122-130. https://doi.org/10.1207/s15327965pli0402_12

Yarkoni, T. (2015). Neurobiological substrates of personality: A critical overview. In M. Mikulincer, P. R. Shaver, M. L. Cooper, \& R. J. Larsen (Eds.), APA handbook of personality and social psychology: Vol. 4: Personality processes and individual differences (pp. 61-83). American Psychological Association. https://doi.org/10.1037/14343-003 